\title{
TAMANHO DE RECIPIENTES E TEMPO DE FORMAÇÃO DE MUDAS NO DESENVOLVIMENTO E PRODUÇÃO DE MARACUJAZEIRO-AMARELO ${ }^{1}$
}

\author{
PAULO VICENTE CONTADOR ZACCHEO ${ }^{2}$, RICARDO SFEIR DE AGUIAR ${ }^{3}$, \\ NEUSA MARIA COLAUTO STENZEL ${ }^{4}$, CARMEN SILVIA VIEIRA JANEIRO NEVES ${ }^{5}$
}

RESUMO-O tamanho de recipientes e o tempo de formação em viveiro são fatores diretamente relacionados com a qualidade das mudas de maracujazeiro, mas é importante verificar se o maior desenvolvimento da muda se reflete no desempenho das plantas adultas a campo. Assim, o objetivo deste trabalho foi avaliar a influência do tamanho de recipientes e do tempo de formação das mudas no desenvolvimento e na produção de maracujazeiro-amarelo. O delineamento experimental utilizado foi de blocos ao acaso, arranjados em esquema fatorial 3 (tamanhos de recipientes) x 3 (períodos de formação das mudas), com quatro repetições e quatro plantas por parcela. Os recipientes avaliados tinham volumes de $400 ; 800 \mathrm{e} 1.200 \mathrm{~cm}^{3}$, e as semeaduras foram realizadas em março, abril e maio. As mudas foram transplantadas para o campo,em setembro, com 180; 150 e 120 dias de formação em viveiro. Foram avaliados a altura das mudas no transplante, a produção total, o número de frutos por planta e a massa dos frutos durante o $1^{\circ}$ ciclo de produção. O desenvolvimento vegetativo da parte aérea das mudas é proporcional ao tamanho do recipiente e ao tempo para formação. Semeaduras realizadas no mês de maio, em recipientes de $1.200 \mathrm{~cm}^{3}$, são mais apropriadas por apresentarem produção de frutos maior e/ou igual aos demais tratamentos, em menor período de formação.

Termos para indexação: Passiflora edulis, propagação, viveiro.

\section{SIZE OF CONTAINERS AND PERIOD OF SEEDLINGS FORMATION IN YELLOW PASSION FRUIT DEVELOPMENT AND PRODUCTION}

\begin{abstract}
The size of containers and the period of seedling formation in the nursery are factors directly related with the quality of passion fruits seedlings, but it is important also to check out if the development in the nursery is reflected in the performance of adult plants in the field. . The aim of this study was to evaluate the effect of the size of containers and the period of seedling formation in yellow passion fruit development and production. The experimental design was a randomized block, arranged in a factorial 3 (sizes of containers) $\mathrm{x} 3$ (periods of seedling formation) with four replications and four plants per plot. The containers evaluated had volume of 400, 800 to 1,200 $\mathrm{cm}^{3}$ and the seeds were sowed in March, April and May. The seedlings were transplanted to the field in September, at the age of 180,150 and 120 days old. The height of the seedlings in the transplant, total crop production, number of fruits per plant and fruit mass during the first cycle of crop production were evaluated. The vegetative growth of the seedlings is proportional to the size of the container and to the time for formation. Sowing in May in $1,200 \mathrm{~cm}^{3}$ is more appropriate because plants have higher or equal fruit production to the other treatments in a shorter period of formation in the nursery. Index terms: Passiflora edulis, propagation, nursery.
\end{abstract}

\footnotetext{
1(Trabalho 277-12). Recebido em: 09-11-2012. Aceito para publicação em: 19-04-2013.

${ }^{2}$ Eng. Agr. MSc. Doutorando do Programa de Pós graduação em Agronomia, Universidade Estadual de Londrina. E-mail: pvczaccheo@ yahoo.com.br

${ }^{3}$ Eng. Agr. MSc. Doutorando do Programa de Pós graduação em Agronomia, Universidade Estadual de Londrina. E-mail: rsaguiar@ hotmail.com

${ }^{4} E_{n}{ }^{\mathrm{a}}$. Agr ${ }^{\mathrm{a}}$. Dr ${ }^{\mathrm{a}}$. Pesquisadora do Instituto Agronômico do Paraná. E-mail: nstenzel@iapar.br

${ }^{5} \mathrm{Eng}^{\mathrm{a}}$. Agr ${ }^{\mathrm{a}}$. Dr ${ }^{\mathrm{a}}$. Professora da Universidade Estadual de Londrina. E-mail: csvjneve@uel.br
} 


\section{INTRODUÇÃO}

O maracujazeiro apresenta grande importância no setor agrícola mundial devido às características físico-químicas dos frutos e aos efeitos farmacoterápicos, resultando em grande aceitação no mercado (FREITAS et al., 2011). No Brasil, maior produtor mundial, é cultivado em cerca de 50 mil hectares, com uma produção estimada de 720 mil toneladas (POLL et al., 2011).

A multiplicação do maracujazeiro é geralmente feita através de sementes, embora também ( MELETTI, 2011) possa ser realizada por meio de enxertia e estaquia. As mudas são conduzidas, preferencialmente, em recipientes individuais, por proporcionarem maior precocidade às plantas, menor possibilidade de contaminação por fitopatógenos, melhor controle ambiental, melhor aproveitamento das sementes e da área de produção de mudas, e menor estresse no transplante (RONCATTO et al., 2008).

Para se obter alta produtividade e frutos de qualidade, é necessária a utilização de uma boa técnica de formação de mudas, pois estima-se que $60 \%$ do sucesso de uma cultura está em implantá-la com mudas de qualidade. Um dos fatores relacionados à qualidade das mudas é o tamanho do recipiente utilizado. A utilização de recipientes com volumes superiores a $500 \mathrm{~cm}^{3}$ favorece o desenvolvimento do sistema radicular e da parte aérea do maracujazeiro (PIO et al., 2004). Contudo, o uso de grandes recipientes impacta diretamente o custo final de mudas em geral, pois influencia na quantidade do substrato e insumos, no espaço que irá ocupar no viveiro, na mão de obra utilizada no transporte e na remoção para aclimatação (QUEIROZ; MELÉM JÚNIOR, 2001).

O tempo de formação das mudas é outro fator importante a considerar. Mudas com períodos mais longos de formação tendem a apresentar maior desenvolvimento da parte aérea e das raízes no momento do transplante, o que pode contribuir para antecipar o florescimento e, consequentemente, aumentar o ciclo de produção, com reflexos diretos na produtividade da cultura (VERDIAL et al., 2000). Por outro lado, quanto mais tempo na fase de viveiro, maior o crescimento do sistema radicular e, consequentemente, maior é o risco de danos no transplante, que podem à redução na produtividade.

$\mathrm{Na}$ maioria dos estudos que envolvem a tecnologia de produção de mudas frutíferas, os pesquisadores avaliam o desenvolvimento das plantas apenas até a fase em que estas devem ser transplantadas para o campo. Porém, é de grande importância relacionar o desempenho das plantas na fase de formação com o seu desenvolvimento e produção no campo, principalmente considerando os fatores relacionados ao estresse provocado pelo transplante.

Assim, torna-se necessária a execução de pesquisas visando à otimização dos fatores envolvidos na propagação do maracujazeiro. $\mathrm{O}$ objetivo deste trabalho foi avaliar a influência do tamanho de recipientes e do tempo de formação das mudas no desenvolvimento e na produção da primeira safra de maracujazeiro-amarelo.

\section{MATERIAL E MÉTODOS}

O experimento foi conduzido no município de Londrina-PR, em área experimental do Instituto Agronômico do Paraná (IAPAR), situado a $23^{\circ}$ $22^{\prime} \mathrm{S}$ e $51^{\circ} 10^{\prime} \mathrm{W}$, com altitude de $585 \mathrm{~m}$. O clima, segundo a classificação de Wilhelm Köeppen, é subtropical úmido (Cfa), com precipitação média anual de $1.500 \mathrm{~mm}$, temperatura média anual de 22 ${ }^{\circ} \mathrm{C}$, evapotranspiração anual de $1.350 \mathrm{~mm}$, umidade relativa anual média de $75 \%$ e insolação média de $7 \mathrm{~h} 14 \mathrm{dia}^{-1}$ (CAVIGLIONE et al., 2000). O solo é classificado, de acordo com Bhering (2007), como Latossolo Vermelho distroférrico, de textura argilosa.

$\mathrm{O}$ delineamento experimental utilizado foi o de blocos ao acaso, arranjados em esquema fatorial 3 (tamanhos de recipientes) x 3 (períodos de formação das mudas), com quatro repetições e quatro plantas por parcela.

Para a formação das mudas, foram utilizadas sementes provenientes de frutos saudáveis e maduros de plantas selecionadas de maracujazeiros-amarelos (Passiflora edulis Sims.), de pomar comercial. Os recipientes testados foram sacos plásticos de polietileno, com volumes de: 400; 800 e 1.200 $\mathrm{cm}^{3}$, denominados neste trabalho como pequeno $(\mathrm{P})$, médio $(\mathrm{M})$ e grande $(\mathrm{G})$, preenchidos com solo peneirado, esterco de curral e areia, na proporção de $3: 1: 1(\mathrm{v} / \mathrm{v} / \mathrm{v})$. As semeaduras foram realizadas em 15 de março, 17 de abril e 15 de maio, e as mudas foram conduzidas em viveiro telado, sob irrigação diária, até o transplante. Em meados de setembro, com aproximadamente $180 ; 150$ e 120 dias de formação, as mudas foram transplantadas para o campo, com espaçamento de 3,0 $\mathrm{m}$ na linha e 3,5 $\mathrm{m}$ na entrelinha (952 plantas por ha). O sistema de condução e sustentação utilizado foi o de espaldeira vertical, com os mourões a uma distância de $6,0 \mathrm{~m}$ e um fio de arame liso a 1,8 $\mathrm{m}$ de altura em relação ao solo. As plantas foram conduzidas em haste única até o fio de arame, e os ramos secundários, orientados para uma única direção, para evitar o entrelaçamento dos mesmos entre as plantas das 
parcelas vizinhas. As plantas não foram polinizadas artificialmente, a área não foi irrigada e o controle de plantas daninhas foi realizado por meio de roçada das entrelinhas. A adubação foi realizada com $1.175 \mathrm{~g}$ de sulfato de amônio, $320 \mathrm{~g}$ de superfosfato simples e $580 \mathrm{~g}$ de cloreto de potássio por planta, divididos em 9; 2 (durante o preparo da cova e no plantio) e 7 aplicações, respectivamente, mediante análise prévia do solo.

Foram determinados a altura das mudas $(\mathrm{cm})$, a produção total (kg por planta), o número de frutos por planta e a massa dos frutos (g). As avaliações para altura das plantas foram realizadas na fase de transplante e, durante $o 1^{\circ}$ ciclo de produção da cultura, entre os meses de fevereiro e maio, sendo as demais variáveis avaliadas mediante coletas semanais dos frutos maduros, considerando-se todas as plantas da parcela. Os dados foram submetidos à análise de variância complementada, pelo teste de Tukey, a 5\% de significância.

\section{RESULTADOS E DISCUSSÃO}

Houve interação significativa entre o tamanho dos recipientes e os períodos de formação das mudas para altura das plantas (Tabela 1). Como era esperado, as mudas formadas no recipiente grande apresentaram maior altura em relação às formadas no recipiente pequeno, nos três períodos de formação, embora não tenham diferido das formadas no recipiente médio, com 150 e 120 dias. Verificou-se ainda que, independentemente do recipiente, as mudas formadas com 180 dias superaram as formadas nos demais períodos, o que também era previsto, considerando que as mudas que permaneceram mais tempo no viveiro tiveram mais oportunidade de se desenvolver.

As mudas que obtiveram maior altura foram aquelas que corresponderam ao período de formação de 180 dias (Tabela 1), porém as mudas formadas no recipiente grande, com 150 e 120 dias, tiveram maior produção total quando comparadas às de 180 dias e, para as demais variáveis, não houve diferenças significativas entre os períodos de formação. Esses resultados contradizem Verdial et al. (2000), que afirmam que, para o maracujazeiro-amarelo, mudas maiores tendem a formar plantas mais desenvolvidas com possíveis reflexos positivos na produtividade da cultura. Além disso, espera-se também que plantas provenientes de mudas maiores entrem em produção mais cedo, resultando em maior período de colheita e maior produção, o que não foi verificado no presente trabalho, uma vez que todos os tratamentos foram colhidos entre os meses de fevereiro e maio.
Este resultado contraditório pode estar relacionado com as deformações do sistema radicular causadas pelo limitado espaço físico dos recipientes que ocorrem quando as mudas permanecem por longos períodos em formação. Aguiar et al. (2006), avaliando a conformação do sistema radicular de mudas de videira, em períodos de 60; 90; 120; 150 e 180 dias de formação, concluíram que o transplante deveria ser realizado até 90 dias, porque, após esse período, as raízes mostraram-se deformadas e enoveladas, o que poderia prejudicar o desenvolvimento da planta adulta e, consequentemente, a produção. Além disso, raízes deformadas tendem a prejudicar a partição de carboidratos, a produção e o transporte de reguladores de crescimento e a absorção de água e nutrientes. Assim, devido ao maior tempo de formação, as raízes das mudas de maracujazeiro-amarelo, com 180 dias, podem ter sido suprimidas pelo recipiente, o que refletiu na produção de frutos da planta adulta.

Para a produção total, também foi verificada interação significativa entre o tamanho dos recipientes e os períodos de formação das mudas (Tabela 1). Mudas formadas em recipientes de tamanho grande, por um período de 120 e 150 dias, apresentaram-se mais produtivas, diferenciando-se daquelas produzidas em 180 dias. Os baixos valores determinados para essa variável (17,6 a 22,1 kg por planta) podem estar relacionados ao período reprodutivo do experimento, visto que a avaliação dos tratamentos foi realizada no período denominado safrinha (fevereiro a maio), que apresenta produção naturalmente mais baixa em relação à safra, que ocorre de dezembro a julho.

Com relação ao número de frutos por planta, foi observado diferença significativa, desdobrando-se a variável tamanho do recipiente dentro do período de formação das mudas de 120 dias (Tabela 1). Nesse período, as plantas provenientes de mudas formadas no recipiente grande apresentaram maior número de frutos que as do recipiente pequeno, sem diferir das produzidas no recipiente médio. Estes resultados podem ser explicados pelo maior desenvolvimento do sistema radicular das plantas que permanecem mais tempo no viveiro e, em consequência disso, sofrem maior estresse no transplante, o que reduz a produtividade.

Para a massa dos frutos, não foi verificada interação ou diferença significativa entre as variáveis (Tabela 1). Os valores máximo e mínimo foram de 177,5 e 156,5 g para mudas formadas no recipiente pequeno, com 120 e 180 dias, respectivamente, indicando que o maior desenvolvimento das plantas na fase inicial, apesar de interferir na produtividade, não afeta a qualidade dos frutos.

No geral, foi verificado que o tamanho do 
recipiente exerce influência positiva no desenvolvimento e, consequentemente, nos caracteres produtivos do maracujazeiro. Por apresentar maior volume, o recipiente grande destacou-se em relação aos demais (Tabela 1). Isto se deve principalmente à maior quantidade de substrato disponível, acarretando em maior disponibilidade de nutrientes; ao maior volume útil passivo de exploração pelas raízes, e à melhor distribuição das mudas na fase de viveiro, visto que o maior diâmetro do recipiente proporciona maior espaçamento entre as plantas, diminuindo a competição pela luz (RIBEIRO et al., 2005).

Outros autores também observaram o efeito de recipientes no desenvolvimento de mudas de maracujazeiro ao avaliarem outras variáveis, como número de folhas, massa seca da parte aérea e das raízes, além da altura das plantas (COSTA et al., 2009; RIBEIRO et al., 2005; PIO et al., 2004; VERDIAL et al., 2000; OLIVEIRA et al., 1993). Foi verificado em todos estes trabalhos que as mudas formadas em recipientes maiores superaram as formadas em recipientes menores para as variáveis citadas. Entretanto, Silva et al. (2010), ao avaliarem o desenvolvimento de mudas de maracujazeiro-amarelo em recipientes com volumes de 1.000 e de $700 \mathrm{~cm}^{3}$, não observaram diferença significativa, o que pode ser explicado pela pequena diferença de volume entre os dois recipientes estudados.

TABELA 1- Altura das mudas, produção total, número de frutos por planta e massa dos frutos de maracujazeiro-amarelo formado em três tamanhos de recipientes e em três períodos. Londrina-PR.

\begin{tabular}{|c|c|c|c|c|}
\hline \multirow[b]{2}{*}{ Tamanho do recipiente } & \multicolumn{3}{|c|}{ Períodos de formação das mudas } & \multirow[b]{2}{*}{ Média } \\
\hline & 180 dias & 150 dias & 120 dias & \\
\hline & \multicolumn{4}{|c|}{ Altura das mudas $(\mathrm{cm})$} \\
\hline $\mathrm{P}\left(400 \mathrm{~cm}^{3}\right)$ & $83,0 \mathrm{Ca}^{1}$ & $25,4 \mathrm{Bb}$ & $59,2 \mathrm{Bab}$ & 55,9 \\
\hline $\mathrm{M}\left(800 \mathrm{~cm}^{3}\right)$ & $135,7 \mathrm{Ba}$ & $92,2 \mathrm{Ab}$ & $93,2 \mathrm{ABb}$ & 107,0 \\
\hline $\mathrm{G}\left(1.200 \mathrm{~cm}^{3}\right)$ & $207,8 \mathrm{Aa}$ & $128,3 \mathrm{Ab}$ & $106,9 \mathrm{Ab}$ & 147,7 \\
\hline Média & 142,2 & 81,9 & 86,5 & \\
\hline \multicolumn{5}{|l|}{$\mathrm{CV}=22,28 \%$} \\
\hline & \multicolumn{4}{|c|}{ Produção (kg por planta) } \\
\hline $\mathrm{P}\left(400 \mathrm{~cm}^{3}\right)$ & $18,9 \mathrm{Aa}$ & $18,5 \mathrm{Aa}$ & $18,3 \mathrm{Ba}$ & 18,6 \\
\hline $\mathrm{M}\left(800 \mathrm{~cm}^{3}\right)$ & $19,3 \mathrm{Aa}$ & $19,2 \mathrm{Aa}$ & $19,2 \mathrm{ABa}$ & 19,2 \\
\hline $\mathrm{G}\left(1.200 \mathrm{~cm}^{3}\right)$ & $17,6 \mathrm{Ab}$ & $22,0 \mathrm{Aa}$ & $22,1 \mathrm{Aa}$ & 20,6 \\
\hline Média & 18,6 & 19,9 & 19,9 & \\
\hline \multicolumn{5}{|l|}{$\mathrm{CV}=10,02 \%$} \\
\hline & \multicolumn{4}{|c|}{ Número de frutos por planta } \\
\hline $\mathrm{P}\left(400 \mathrm{~cm}^{3}\right)$ & $121,3 \mathrm{Aa}$ & $112,4 \mathrm{Aa}$ & $104,6 \mathrm{Ba}$ & 112,8 \\
\hline $\mathrm{M}\left(800 \mathrm{~cm}^{3}\right)$ & $111,3 \mathrm{Aa}$ & $113,9 \mathrm{Aa}$ & $110,1 \mathrm{ABa}$ & 111,8 \\
\hline $\mathrm{G}\left(1.200 \mathrm{~cm}^{3}\right)$ & $105,6 \mathrm{Aa}$ & $128,2 \mathrm{Aa}$ & $128,0 \mathrm{Aa}$ & 120,6 \\
\hline Média & 112,7 & 118,2 & 114,2 & \\
\hline \multicolumn{5}{|l|}{$\mathrm{CV}=11,48 \%$} \\
\hline & \multicolumn{4}{|c|}{ Massa dos frutos (g por fruto) } \\
\hline$P\left(400 \mathrm{~cm}^{3}\right)$ & $156,5^{\text {ns }}$ & 166,5 & 177,5 & 166,8 \\
\hline $\mathrm{M}\left(800 \mathrm{~cm}^{3}\right)$ & 175,3 & 170,3 & 174,9 & 173,5 \\
\hline $\mathrm{G}\left(1.200 \mathrm{~cm}^{3}\right)$ & 166,9 & 171,3 & 172,9 & 170,3 \\
\hline Média & 166,2 & 169,4 & 175,1 & \\
\hline $\mathrm{CV}=9,15 \%$ & & & & \\
\hline
\end{tabular}

${ }^{1}$ Médias seguidas da mesma letra, maiúscula na coluna e minúscula na linha, não diferem entre si, pelo teste de Tukey, a $5 \%$ de significância. ${ }^{\text {ns: }}$ diferença não significativa. 


\section{CONCLUSÕES}

1-O desenvolvimento vegetativo da parte aérea das mudas é proporcional ao tamanho do recipiente e ao tempo para formação.

2-Mudas com semeadura realizada no mês de maio, formadas em recipientes de $1.200 \mathrm{~cm}^{3} \mathrm{e}$ plantadas em setembro no norte do Paraná, são mais apropriadas, por mostrarem menor período (120 dias) para a formação, além de resultar em produção de frutos maior e/ou igual quando comparada aos outros tratamentos.

3-O tamanho do recipiente e o tempo para a formação das mudas não interferem na massa média dos frutos.

\section{REFERÊNCIAS}

AGUIAR, R. S. de; NEVES, C. S. V. J.; ROBERTO, S. R.; SANTOS, C. E. dos; GENTA, W. Arquitetura do sistema radicular do porta-enxerto de videira'IAC 766' na época de transplante do viveiro para o campo. Revista Brasileira de Fruticultura, Jaboticabal, v. 28, n. 3, p. 402-405, 2006.

BHERING, S. B. Mapa de solos do Estado do Paraná. Rio de Janeiro: Embrapa Solos, 2007. (Documentos).

CAVIGLIONE, J. H.; KIIHL, L. R. B.; CARAMORI, P. H.; OLIVEIRA, D. Cartas climáticas do Paraná. Londrina: IAPAR, 2000. CD-ROM.

COSTA, E.; RODRIGUES, E. T.; ALVES, V. B.; SANTOS, L. C. R. dos; VIEIRA, L. C. R. Efeitos da ambiência, recipientes e substratos no desenvolvimento de mudas de maracujazeiroamarelo em Aquidauana - MS. Revista Brasileira de Fruticultura, Jaboticabal, v. 31, n. 1, p. 236-244, 2009.

FREITAS, J. P. X. de; OLIVEIRA, E. J. de; CRUZ NETO, A. J. da; SANTOS, L. R. dos. Avaliação de recursos genéticos de maracujazeiro-amarelo. Pesquisa Agropecuária Brasileira, Brasília, v. 46, n. 9, p. 1013-1020, 2011.

MELETTI, L.M. Avanços na cultura do maracujá no Brasil. Revista Brasileira de Fruticultura. Jaboticabal, v. 33, n.1 edição especial. p. 83 - 90, 2011.
OLIVEIRA R.P. de; SCIVITTARO W. B.; VASCONCELLOS L. A. B. C. de. Avaliação de mudas de maracujazeiro em função do substrato e do tipo de bandeja. Scientia Agricola, Piracicaba, v. 50, n. 2, p. 261-266, 1993.

PIO, R.; RAMOS, J. D.; GONTIJO, T. C. A.; TOLEDO, M; CARRIJO, E. P.; VISIOLI, E. L.; TOMASETTO, F.; MENDONÇA, V. Influência de diferentes recipientes e ambientes na produção de mudas de maracujazeiro-doce. Revista de Ciências Agrárias, Belém, n. 41, p. 127-135, 2004.

POLL, H.; BENNO, A. Z. V.; KIST, B.; SANTOS, C.; CARVALHO, C.; REETZ, E. R.; BELING, R. R. Anuário brasileiro da fruticultura 2011. Santa Cruz do Sul: Editora Gazeta Santa Cruz, 2011. p.128.

QUEIROZ, J.A.; MELÉM JÚNIOR, N.J. Efeito do tamanho do recipiente sobre o desenvolvimento de mudas de açaí (Euterpe olaracea Mart.). Revista Brasileira de Fruticultura, Jaboticabal, v.21, n.1, p.460-462, 2001.

RIBEIRO, M. C. C.; MORAIS, M. J.A. de; SOUSA, A. H. de; LINHARES, P. C. F.; BARROS JÚNIOR, A. P. Produção de mudas de maracujá-amarelo com diferentes substratos e recipientes. Caatinga, Mossoró, v.18, n.3, p.155-158, 2005.

RONCATTO, G; NOGUEIRA FILHO, G. C.; RUGGIERO, C.; OLIVEIRA, J. C. de; MARTINS, A. B. G. Enraizamento de estacas herbáceas de diferentes espécies de maracujazeiro. Revista Brasileira de Fruticultura, Jaboticabal, v.30, n.4, p.1094-1099 2008.

SILVA, E.A. da; MARUYAMA, W. I.; MENDONÇA, V.; FRANCISCO, M. G. S.; BARDIVIESSO, D. M.; TOSTA, M. da S. Composição de substratos e tamanho de recipientes na produção e qualidade das mudas de maracujazeiro 'amarelo'. Ciência e Agrotecnologia, Lavras, v. 34, n. 3, p. 588-595, 2010.

VERDIAL, M. F.; LIMA, M. S. de; TESSARIOLI NETO, J.; DIAS, C. T. dos S.; BARBANO, M. T. Métodos de formação de mudas de maracujazeiro amarelo. Scientia Agricola, Piracicaba, v. 57, n. 4, p. $795-798,2000$. 